\title{
Stargardt's disease is not allelic to the genes for neuronal ceroid lipofuscinoses
}

Sylvie Gerber, Sylvie Odent, Anne Postel-Vinay, Nicolas Janin, Jean-Louis Dufier, Arnold Munnich, Jean Frezal, Josseline Kaplan

\begin{abstract}
Stargardt's disease is an autosomal recessive condition characterised by a rapid and bilateral loss of central vision at around 7 to 12 years, with typical changes in the macular and perimacular region. It is one of the most frequent causes of macular degeneration in childhood and accounts for $7 \%$ of all retinal dystrophies. Considering that inclusions of lipofuscin-like substances are observed in retinal pigmentary cells of patients with Stargardt's disease on the one hand, and that the early symptoms of neuronal ceroid lipofuscinosis (CLN3) are suggestive of Stargardt's disease on the other hand (age of loss of visual acuity, appearance of the fundus), we decided to test allelism of Stargardt's disease with the infantile (CLN1) and juvenile forms of neuronal ceroid lipofuscinosis (CLN3), which map to chromosomes 1p32 and 16p12-p11 respectively. Using highly informative microsatellite DNA markers in eight multiplex families, we were able to exclude Stargardt's disease from the vicinity of the CLN1 and CLN3 loci. These results strongly reject the hypothesis of allelism of Stargardt's disease with the neuronal forms of ceroid lipofuscinosis.
\end{abstract}

\section{(f Med Genet 1994;31:222-223)}

Stargardt's disease is an autosomal recessive condition of childhood, characterised by a sudden and bilateral loss of central vision. ${ }^{1}$ This disease (MIM 248200) ${ }^{2}$ is a frequent cause of macular degeneration in children and accounts for $7 \%$ of all retinal dystrophies. ${ }^{3}$ It has an early onset (7 to 12 years), a rapidly progressive course, and a poor final visual outcome. The central area of the retina (macula) displays typical pigmentary changes in a ring form with depigmentation and atrophy of the retinal pigmentary epithelium (RPE), but the rest of the fundus is normal. The visual field shows a central scotoma, the electroretinogram (ERG) shows either a normal response or a selective alteration of the photopic function, and fluorescein angiography shows the "bull's eye phenomenon", consisting of a dark hypofluorescent centre ("dark choroid") ${ }^{4}$ with a ring of hyperfluorescent spots around it ("window effect"').

Interestingly, variable sizes of retinal pigmentary cells with inclusions of lipofuscin-like substances have been reported in the disease, attributing the "dark choroid" effect to the accumulation of lipofuscin. ${ }^{5}$ For this reason, we tested allelism of Stargardt's disease with the infantile (CLN1) and juvenile forms of neuronal ceroid lipofuscinosis (LN3), which map to chromosomes $1 \mathrm{p} 32$ and $16 \mathrm{p} 12-\mathrm{p} 11$ respectively, ${ }^{67}$ especially as the early symptoms of CLN3 are suggestive of Stargardt's disease (age of loss of visual acuity, appearance of the fundus). Here, we show that Stargardt's disease is not linked to either locus.

\section{Patients}

Twenty four affected persons and 42 relatives belonging to eight multiplex families (fig 1) were recruited in France. The minimal diagnostic criteria were: (1) sudden loss of visual acuity between 7 and 12 years of age; (2) ophthalmoscopic evidence for alteration of the macula; (3) normal appearance of the peripheral retina and normal calibre of retinal vessels with no pigmented bone spicules; (4) typical visual field showing a central scotoma; (5) fluorescein angiography showing the "dark choroid" effect; (6) abnormal colour vision showing deuteranopia or protanopia; (7) finally, normal or abnormal photopic ERG. The minimum criteria for inclusion in the study were families with at least two affected children of either sex born to healthy parents.

Results and discussion

Hypervariable microsatellites linked to the CLN1 and CLN3 gene loci on chromosomes
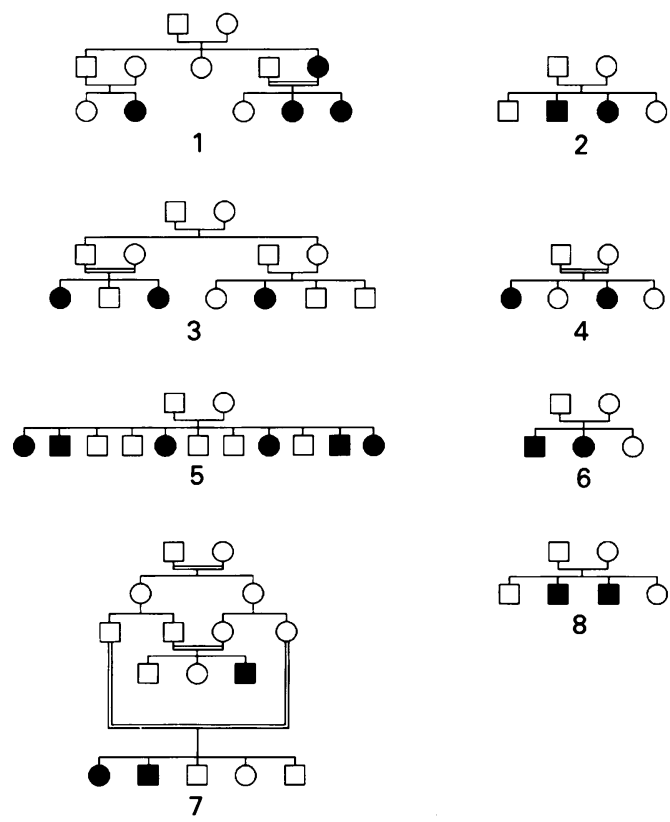

Figure 1 Families with Stargardt's disease. 
Pairwise lod scores between Stargardt's disease gene and markers on chromosomes $1 p 32$ and 16p12-16cen

\begin{tabular}{|c|c|c|c|c|c|c|c|c|c|c|}
\hline \multirow[b]{2}{*}{ Probe } & \multirow[b]{2}{*}{ Locus } & \multicolumn{9}{|c|}{ Recombination fraction $\theta$} \\
\hline & & 0 & 0.01 & 0.05 & 0.1 & 0.2 & 0.3 & 0.4 & $Z \max$ & $\theta \max$ \\
\hline $\begin{array}{l}\text { AFM260zg5 } \\
\text { AFM198ye9 } \\
\text { AFM120xd4 } \\
\text { AFM165yb6 } \\
\text { AFM049xd2 } \\
\text { AFM025tg9 } \\
\text { AFM161xa1 }\end{array}$ & $\begin{array}{l}\text { D1S255 } \\
\text { D1S232 } \\
\text { D1S209 } \\
\text { D16S410 } \\
\text { D16S403 } \\
\text { D16S401 } \\
\text { D16S409 }\end{array}$ & $\begin{array}{l}-x \\
-x \\
-x \\
-x \\
-x \\
-x \\
-x\end{array}$ & $\begin{array}{l}-10 \cdot 79 \\
-7 \cdot 90 \\
-4.58 \\
-14 \cdot 68 \\
-4.54 \\
-12 \cdot 24 \\
-12.19\end{array}$ & $\begin{array}{l}-5.35 \\
-3.35 \\
-1.97 \\
-7.20 \\
-1.41 \\
-7.58 \\
-5.63\end{array}$ & $\begin{array}{l}-3 \cdot 20 \\
-1.68 \\
-1 \cdot 0 \\
-4 \cdot 21 \\
-0.37 \\
-3.03 \\
-3.15\end{array}$ & $\begin{array}{r}-1.29 \\
-0.49 \\
-0.27 \\
-1.67 \\
0.21 \\
-1.03 \\
-1.16\end{array}$ & $\begin{array}{r}-0.47 \\
-0.13 \\
-0.05 \\
-0.60 \\
0.21 \\
-0.32 \\
-0.40\end{array}$ & $\begin{array}{r}-0.11 \\
-0.04 \\
-0.01 \\
-0.13 \\
0.07 \\
-0.07 \\
-0.09\end{array}$ & $\begin{array}{l}0 \\
0 \\
0 \\
0 \\
0 \cdot 23 \\
0 \\
0\end{array}$ & $\begin{array}{l}0.50 \\
0.50 \\
0.50 \\
0.50 \\
0.25 \\
0.50 \\
0.50\end{array}$ \\
\hline
\end{tabular}

$1 \mathrm{p} 32$ and $16 \mathrm{p} 12$ respectively were chosen from the Génethon linkage map on the basis of their informativeness, at an average genetic distance of $\theta<=0 \cdot 1$ (table). The orders:
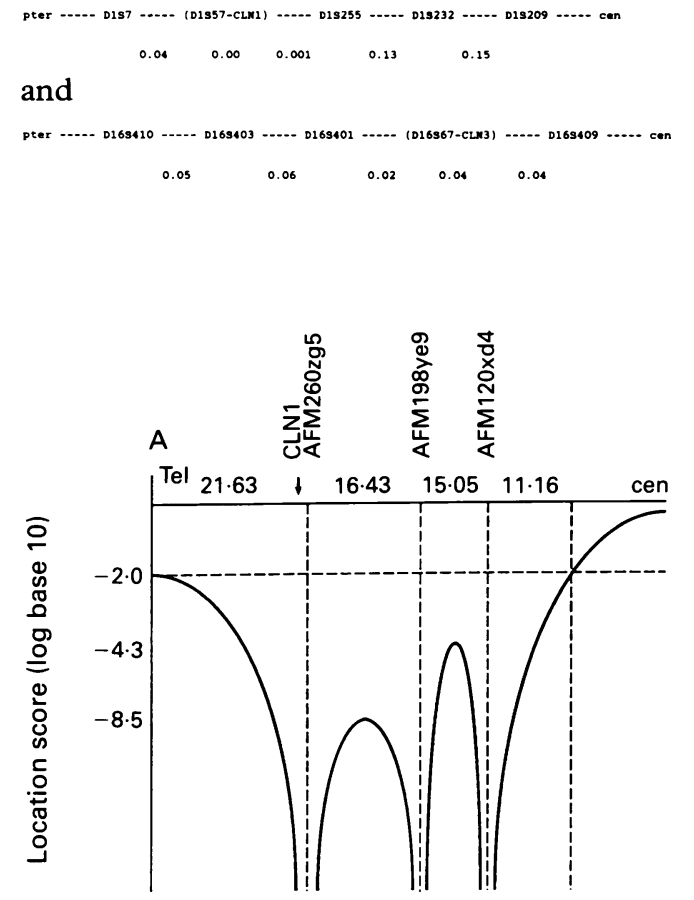

Genetic location (cM) on chromosome 1p

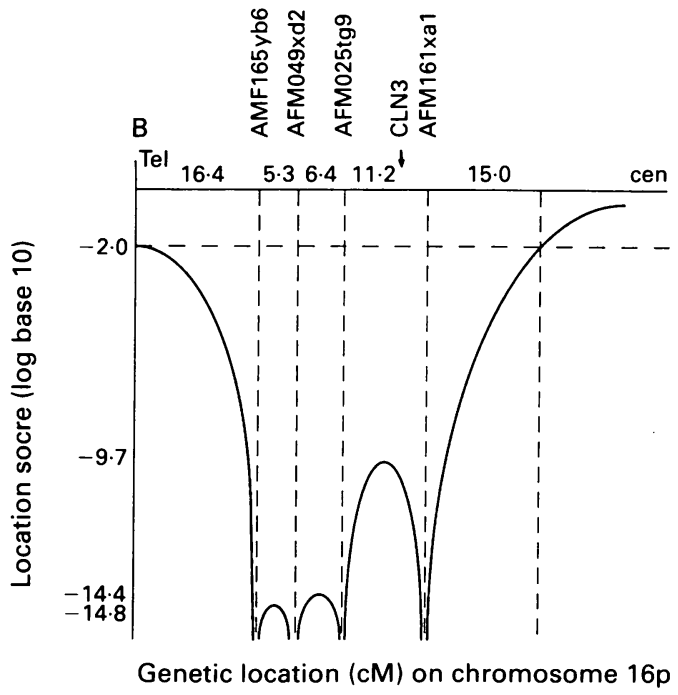

Figure 2 Multipoint analysis. ( $A$ ) Exclusion of the Stargardt's disease gene from a $64 \mathrm{cM}$ region of chromosome 1 p 32 . Distances between markers were fixed according to the Génethon Data Base. (B) Exclusion of the Stargardt's disease gene from a $54 \mathrm{cM}$ region of chromosome 16p12-p11. Distances between markers were fixed according to the Génethon Data Base. were previously established by analysis of CEPH reference families ${ }^{8}$ (J Weissenbach, personal communication). Genotyping was carried out as previously described ${ }^{8}$ and linkage analysis was performed using the MLINK and LINKMAP options of the 5.1 version of the LINKAGE program. Negative lod score values with probes AFM260zg5, AFM198ye9, and AFM120xd4 at loci D1S255, D1S232, and D1S209 were obtained for each family and the combined families, excluding the Stargardt gene from close proximity to the CLN1 gene on chromosome $1 \mathrm{p} 32$ (table). Multipoint analysis excluded the Stargardt gene from a large area $(64.3 \mathrm{cM})$ including the CLN1 locus on the short arm of chromosome lp (fig 2A). Similarly, negative lod score values were obtained with probes AFM165yb6, AFM049xd2, AFM025tg9, and AFM161wal at loci D16S410, D16S403, D16S401, and D16S409 respectively, excluding the disease gene from the vicinity of the CLN3 gene (table, fig 2B).

The present study excludes the Stargardt gene from close proximity to the CLN1 and CLN3 genes in eight informative families and strongly rejects the hypothesis of allelism of Stargardt's disease with the neuronal forms of ceroid lipofuscinoses.

We are grateful to Jean Weissenbach and Alain Vignal from Généthon for helpful discussion and preliminary information on unpublished polymorphic DNA markers. We thank Monique Poussière for her help in preparing this manuscript. This que Poussiere for her help in preparing this manuscript. This pathies (AFM), Association Française Retinitis Pigmentosa pathies (AFM), Association Française
(ARFP), and Institut Electricité Santé.

1 Stargardt K. Uber Familiäre, progressive degeneration under makulagegend des Auges. Albrecht von Graefes Arch Ophthalmol 1909;71:534-50.

2 McKusick VA. Mendelian inheritance in man. 10th ed. Baltimore: Johns Hopkins University Press, 1992.

3 Kaplan J, Bonneau D, Frézal J, Munnich A, Dufier JL. Clinical and genetic heterogeneity in retinitis pigmentosa. Hum Genet 1990;85:635-42.

4 Fish G, Grey R, Sehmi KS, Bird AC. The dark choroid in posterior retinal dystrophies. $\mathrm{Br} f$ Ophthalmol 1981;65:359-63.

5 Maumenee IH, Maumenee AE. Fundus flavimaculatus: clinical, genetic and pathologic observations. In: François J, ed. Fifth Congress of the European Society of Ophthalmology, Hamburg, 1976. Stuttgart: Ferdinant Enke 1978:802 .

6 Jarvela I, Schleutker J, Haataya L, et al. Infantile form of neuronal ceroid lipofuscinosis (CLN1) maps to the short arm of chromosome 1. Genomics 1991;9:170-3.

7 Mitchison HM, Thompson AD, Mulley JC, et al. Fine genetic mapping of the Batten disease locus (CLN3) by haplotype analysis and demonstration of allelic association with chromosome $16 \mathrm{p}$ microsatellite loci. Genomics 1993;16:455-60.

8 Weissenbach J, Gyapay G, Dib C, et al. A second-generation linkage map of the human genome. Nature 1992;359:794 801. 